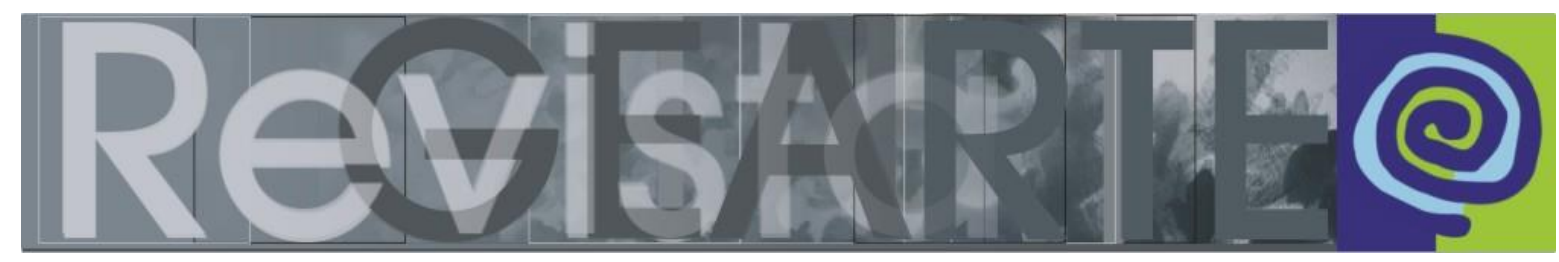

Volume 1, Número 2, Agosto/2014, ISSN 2357-9854

\title{
Mediação cultural como possibilidade de aprendizagem na infância
}

\author{
Silvia Sell Duarte Pillotto (UNIVILLE - Brasil) \\ Letícia Ribas Diefenthaeler Bonh (UNIVILLE - Brasil)
}

\begin{abstract}
RESUMO
A educação infantil praticamente não tem acesso aos espaços culturais locais, especialmente por se pensar que as crianças não têm condições de apreciarem uma exposição de arte ou qualquer outro espaço que demande habilidades cognitivas. A indagação inicial da pesquisa centra-se nas seguintes questões: a mediação cultural pode mobilizar o aprendizado na infância? Como articular a mediação cultural nos espaços formais e não formais da educação, tendo a criança, o professor e o educador de museus como integrantes desses processos? A pesquisa busca refletir sobre outros modos de aprendizagem na infância para além dos muros escolares, com foco na mediação cultural, tendo duas unidades de educação infantil e o Museu Casa Fritz Alt como partícipes nesse processo. Esse artigo faz um recorte do arcabouço conceitual que dará subsídios para o diálogo com a pesquisa de campo, tendo o viés qualitativo como vertente.
\end{abstract}

\section{PALAVRAS-CHAVE}

Mediação cultural; Infância; Educação não formal; práticas educativas.

\section{ABSTRACT}

Early childhood education practically do not have access to local cultural spaces, particularly because there are people who thinks that children does not have conditions to enjoy an art museum, an art gallery or spaces like this, in those it is necessary to have cognitive skills. The central point of this article is based on a few questions, such as: cultural mediation can instigate learning at childhood? What is the right way to introduce cultural mediation in formal and informal education spaces, keeping child, teacher and people who attend at museums as parts of this process? Our research wants to reflect about other ways of learning at childhood, outside of school walls, supported by cultural mediation. We will examinate the examples of two childhood schools and Museu Casa Fritz Alt. This article proposes an approach of the conceptual framework that will provide subsidies for the dialogue with field research taking bias as the qualitative aspect.

\section{KEYWORDS}

Cultural Mediation, Childhood, Informal Education, Educational Practices.

\section{Introdução}

O contexto da educação infantil ganha espaços nos últimos anos, especialmente com a inclusão na Educação Básica, mas, ainda temos resquícios da história em que a criança é limitada em seus processos de aprendizagem, especialmente em se tratando de espaços culturais para além da escola.

Outra questão que merece nossa atenção é a distante relação entre educação formal e não formal, que limita a ampliação dos processos de aprendizagem da 
criança, não englobando os espaços culturais locais como mobilizadores nesse processo.

Outro fator de preocupação é a compreensão sobre mediação cultural. Grosso modo é entendida como trabalho de monitoria desenvolvido em alguns espaços culturais, como: museus, galerias de arte, bienais, etc.

Desta forma, refletir sobre a visitação do público infantil aos espaços culturais locais, enfatizando a mediação cultural como atitude pedagógica dos profissionais envolvidos nesse processo, é um dos desafios dessa pesquisa. O público infantil tem aumentado dia a dia nos espaços culturais, o que evidencia a necessidade de estudos e reflexões para que essa ação contemple, de fato, as especificidades que a criança necessita, possibilitando outras formas de aprendizagens. (GABRE, 2014)

A mediação cultural pressupõe, portanto, uma postura diferenciada no encontro entre arte e cultura e, nesse sentido, os agentes da mediação necessitam compartilhar essa prática. Lima (2009, p.148) afirma que

\footnotetext{
Já não bastam informações e orientações, é preciso construir novos paradigmas de ação que todo o tempo nos diz e nos pede "mediações". É esse estado que gera desafios. E eles se amplificam se considerarmos os diferentes ambientes de apreensão e compreensão.
}

Para um processo constitutivo de conhecimento e saberes, Tamanini e Pillotto (2012, p. 113) afirmam ser necessário que os registros (fotografias, figuras, filmagens, objetos, falas...) sejam instigados a revelar algo mais sobre distintos processos culturais. "Testemunhos do tempo, os artefatos apresentam com singularidade o imaginário social, apontam para as singularidades e subjetividades da experiência humana".

A educação não formal, nesse sentido, possibilita interações com objetos, espaços, saberes, pois diferente da educação formal é menos hierárquica e burocrática, não precisando necessariamente seguir um sistema rígido de ensino e aprendizagem. (GADOTTI, 2005). Configura-se especialmente pela capacidade do mediador em pensar/criar maneiras de experimentar propostas colaborativas de aprendizagem. Barbosa e Coutinho (2009, p. 271) reiteram a importância do diálogo entre educação não formal e formal, afirmando que a educação 
[...] pode contribuir tanto para a permanência como para a renovação e a transformação de modos de olhar, de fazer e de interpretar. Permanência e renovação não são conceitos antagônicos na educação. Ambos fazem parte do processo de aprender e ensinar.

A criança precisa, de novos espaços, novos objetos e imagens para aprender a ver sob novos o olhares. Necessita, sobretudo, de ações lúdicas em que o brincar mistura-se com o apropriar, aprender e relacionar-se com o outro e com o entorno. Para Sarmento (2004, p.23) o mundo da criança "é muito heterogêneo, ela está em contato com várias realidades diferentes, das quais vai aprendendo valores e estratégias que contribuem para a formação da sua identidade pessoal e social." Nas interações da criança com seus pares, com os adultos e com variados espaços culturais é que ela entra em contato com os saberes do mundo, e, num processo constante de vivências vai construindo identidades.

Necessário destacar que, ao pensar nos espaços culturais locais como possibilidades de aprendizagem na infância, a pesquisa tem aprofundado estudos sobre criança/infância, mediação cultural, educação não formal, articulando teoria e prática. Vale aqui destacar que esse artigo faz um recorte do arcabouço conceitual que dará subsídios para o diálogo com a pesquisa de campo.

A pesquisa tem se comprometido em pensar propostas de mediação cultural para a infância, analisando variantes de aprendizagem e reiterando a importância de transcender aos muros escolares, adentrando em outros contextos, outros ambientes e outras maneiras de aprender.

Desta forma, estaremos socializando nesse artigo alguns resultados parciais da pesquisa "mediação cultural como possibilidade de aprendizagem na infância" que tem como objetivo potencializar espaços formais e não formais da educação. Duas unidades de educação infantil (uma pública e outra privada), além de um museu local serão mobilizadores desse processo de mediação cultural para a infância.

\section{Trajetos investigativos em construção}

Com base na vertente qualitativa, a pesquisa "Mediação cultural como possibilidade de aprendizagem na infância" tem seu aporte teórico metodológico referenciado por Flick (2004) e Gatti (2005), apropriando-se das técnicas de observação de campo e grupo focal. 
A observação de campo terá duas etapas: Exposição Itinerante com fotografias das obras do Museu Casa Fritz Alt as duas unidades educacionais envolvidas, e, visita de estudos ao museu de crianças e professores de duas turmas de educação infantil.

A pesquisa contará também com dois grupos focais, um inicial e outro final com o objetivo de ouvir professores e coordenadores das unidades de educação e educadores do Museu Casa Fritz Alt sobre como tratam as questões relacionadas aos espaços culturais locais e aprendizagem na infância. Além de verificar possibilidades de aprendizagens, tendo como veículo a mediação cultural. Registros em fotos e filmagens estão sendo realizados durante todo o processo da pesquisa.

Importante destacar, que durante e após o término da pesquisa, estaremos construindo coletivamente documento com diretrizes sobre mediação cultural para a infância com ênfase em processos de aprendizagem, uma vez que essas experiências poderão sinalizar outras formas de aprendizagem, incluindo vivencias com objetos, imagens, espaços, entre outros.

Após a coleta dos dados, os mesmos serão analisados por meio da metodologia de análise de conteúdo. Como referência temos Bardin (2011) que compreende esse procedimento como uma hermenêutica controlada, baseada em deduções. Trata-se de um leque de apetrechos adaptáveis aos diferentes campos de pesquisa, e que organizados configuram um único instrumento, capaz de constituir a descrição analítica do conteúdo das mensagens.

Na pesquisa, a partir dos grupos focais e observação de campo será possível verificar as várias maneiras de aprendizagem das crianças. As relações de aprendizagem estarão balizadas na relação de imagens de obras de arte de Fritz Alt (exposições itinerantes) e nas visitas de estudos ao referido museu, onde as crianças terão acesso às obras, objetos originais e espaços arquitetônicos.

\section{Compreendendo a criança/infância}

Compreender o que é a infância e que lugar ocupa nos discursos educacionais atuais é o primeiro passo para se buscar ações educacionais consistentes em todas as áreas de formação humana e em diferentes espaços. 
Iniciamos este diálogo trazendo o conceito de infância que alicerça as práticas educacionais no momento atual, apoiadas em Sarmento (2004), afirmando que as crianças são seres biológicos de geração jovem e que sempre existiram. Porém, a ideia de infância como categoria social de estatuto próprio, como construção social, começou a existir a partir dos séculos XVII e XVIII.

A visão e o entendimento da infância acompanham a construção das sociedades e vai modificando a partir das transformações ocorridas nas classes sociais, portanto, o "conjunto de ideias ou imagens que determinadas sociedades constituem sobre a infância podem ser consideradas, enquanto produções humanas, instituindo-se como fenômenos simbólicos, sociais e culturais." (SCHMIDT, 1997 p.10).

Hoje o conceito sobre infância é entendido no plural, falamos em infâncias

[...] a partir da nossa perspectiva pós moderna, não existe algo como 'a criança' ou 'a infância', um ser e um estado essencial esperando para ser descoberto, definido e entendido, de forma que possamos dizer a nós mesmos e aos outros 'o que as crianças são e o que a infância é'. Em vez disso há muitas crianças e muitas infâncias, cada uma construída por nossos 'entendimentos da infância e do que as crianças são e devem ser'. (DAHLBERG, et al. 2003, p.63).

Neste sentido, não há uma definição sobre o que é a infância, ou melhor, o que são as infâncias hoje. O que existe é uma construção e reconstrução constante de conceitos. As crianças são participantes ativas nos processos culturais, consideradas como seres sociais. Portanto, dizer o que são as infâncias hoje depende da postura e visão de cada sujeito e dos significados que atribuem a elas.

Na visão de Chombart de Lauwe (1976) o termo "infância" sinaliza alguns desdobramentos, como: um ser com características singulares marcados pelos acontecimentos; um ser em desenvolvimento, imaturo, que tem comportamentos infantis; um ser inserido no meio social, pertencente a uma família e a culturas que condicionam parte de seu lugar na sociedade; um ser, submetido a um estatuto que, na sociedade dada, determina as características de sua condição de criança.

Nesse lugar social existe "uma relação recíproca entre a criança e o meio, uma inter-relação". (CHOMBART DE LAUWE,1976, p. 37). O comportamento das crianças, portanto, têm variáveis e são complexos não sendo possível explicá-los 
apenas pelas influências sociais ou pelas relações com o outro. Assim, o olhar investigativo sobre a infância e os fenômenos associados a ela devem levar em conta também, não apenas o que elas são, mas, sobretudo, como se constituíram como tal. (BUJES, 2005)

Nesse aspecto Sarmento (2007, p. 37) salienta que não é mais possível então "falar de uma cultura da infância senão com base numa representação que a considere um ser "ativo-interpretativo", personagem marcante na construção social." As crianças não estão inseridas em apenas uma cultura constituída com lugar e papeis sociais definidos pelos adultos, mas são também sujeitos que transforma e se transformam nas culturas. Isso acontece na medida em que as interpretam e as integram, e, na forma como são afetadas pelos efeitos que nela produzem, a partir das suas próprias vivências.

Para Kohan (2005, p. 239)

A infância é a condição de ser afetado que nos acompanha a vida toda. O dito pelo não dito, a falta de palavra, a ausência de voz (in-fans), nos afetos. É aquela singularidade silenciada que não pode ser assimilada pelo sistema. Uma condição de estar afetado que não pode nomear ou reconhecer essa afeição.

Na trajetória da vida, que inicia na infância, construímos sentidos e significados sobre o mundo, apropriando-nos de modos de ser, pensar e sentir. Constituímos assim um repertório de saberes, valores, conhecimentos e experiências. Como afirmam Martins, Picosque e Guerra (1998, p. 21) um "[...] arquivo dinâmico de experiências reais e simbólicas, acervo pessoal de valores, concepções e sentimentos que de certa forma orientam a atribuição de significados e sentidos ao vivido".

Essas experiências devem ser permeadas de ações que alimentem 0 imaginário infantil, mobilizando movimentos de busca e aprendizagens. Implica tempo de espera, de maturação e reflexão. Não acontece imediatamente, pois o tempo linear controlado pelo adulto em suas práticas educativas, nem sempre segue o ritmo do tempo-espera da criança. É fundamental deixar as coisas acontecerem, caso contrário, prevalecerá apenas a lógica do adulto determinada cronologicamente e de forma linear. Isso poderá reduzir as experiências estéticas, culturais e afetivas da criança (OSTETTO, 2006). 
Aos profissionais que trabalham com crianças, é preciso que tenham o entendimento de que toda e qualquer ação da criança permeia a via do lúdico, da experiência e do tempo-espera. É por esse caminho que as práticas nas instituições formais e não formais de educação devem ser pensadas a luz também da criança, um ser em desenvolvimento social e cultural. Sobre essa questão, Dowbor (2007, p. 61) afirma que

Nossa forma de aprender está marcada pela maneira como fomos iniciados nos nossos primeiros contatos com o mundo das pessoas; pela maneira como fomos ensinados a olhar, a falar, a tocar e a perceber as cores e odores do mundo que nos cerca.

Desta forma, a articulação dos espaços formais e não formais tem sido destaque de discussões sobre a sua presença no currículo. Importante refletir, portanto, que essa interação gera principalmente uma educação significativa em que a crítica e a sensibilidade caminham juntas.

\section{Educação não formal e espaços culturais}

A educação é adquirida ao longo da vida dos cidadãos (GOHN, 2008); e consiste no processo de absorção, transformação e reelaboração da cultura existente. Uma das vertentes é a formal, desenvolvida nas escolas oficialmente, ministrada por entidades públicas ou privadas. Presente no ensino escolar institucionalizado tem objetivos claros e específicos; é hierarquicamente estruturada e gradual de forma cronológica, usualmente representada principalmente pelas escolas e universidades.

Os aparelhos escolares institucionalizados com a educação formal foram os mais valorizados até a década de 80 , tanto entre os educadores como no campo de políticas públicas. A partir dos anos 90 , a educação não formal passa a ter grande destaque, em função das mudanças na economia, mundo do trabalho e sociedade. "Passou-se a valorizar os processos de aprendizagem em grupos e a dar-se grande importância aos valores culturais que articulam as ações dos indivíduos" (NICOLA, 2010, p. 92).

A educação, além de ser uma prática social, é também uma prática humana, pois modifica os seres humanos nos seus estados mentais, físicos e culturais, e são estes estados que dão uma configuração à nossa existência humana individual e em grupo (LIBÂNEO, 2005). Assim, o objetivo da prática educativa pode ser o de 
[...] provocar a reconstrução das formas de pensar, sentir e atuar das novas gerações, oferecendo-Ihes como instrumentos ou ferramentas de trabalho os esquemas conceituais que a humanidade foi criando e que se alojam nas diferentes formas de criação cultural (PÉREZ GÒMEZ, 1998, p.100).

A educação não formal denota-se como processos educacionais que são organizados fora da lógica do sistema regular de ensino e não segue um currículo prédefinido baseado nas normas e diretrizes do governo federal. O conteúdo é definido a partir da vontade e das necessidades das pessoas envolvidas.

As atividades educacionais não formais são estruturadas de maneira flexível e com ênfase na prática, fortemente relacionada com o contexto local. É focada em quem aprende e não em quem ensina.

Os elementos que diferenciam a educação não formal da formal são relativos à organização e à estrutura do processo de aprendizagem. Os espaços onde a educação não formal pode se desenvolver são múltiplos: associações, espaços culturais, ONGs e espaços escolares. Entende-se que a educação não formal é qualquer tentativa educacional organizada e sistemática que é realizada fora dos quadros do sistema formal de ensino (BIANCONI; CARUSO, 2005).

Nessa perspectiva, o papel da escola se reinventa, pois segundo Bohn (2014, p. 173) "[...] a escola disposta a extrapolar os próprios muros é aquela que pode balizar conhecimentos empíricos e científicos na perspectiva de construção significativa do eu no mundo a partir do meu local."

Os espaços culturais constituem-se em um sistema, em um espaço que materializa como o tempo é estruturado, estabelecendo, assim, uma conexão entre espaço/tempo e ações desenvolvidas. O uso dos espaços varia conforme as culturas e diz respeito não só às relações humanas, aos conflitos, como também aos ritos sociais e à simbologia.

Segundo Viñao, Frago e Escolano (2001, p. 64) o espaço, enquanto território e lugar induzem à dialética do interno e do externo, o que é a instituição educacional e o que fica fora dela, o aberto e o fechado, o isolamento e a separação, o curvo e o retilíneo. 
A arquitetura das instituições culturais constitui também em um elemento cultural e pedagógico, com forte representação simbólica e influência sobre o sistema social (VAIDERGORN, 2001).

Os espaços culturais para além dos espaços da escola têm em sua conformação múltiplos aspectos, sejam na arquitetura, espaços externos, objetos e artefatos. Esses espaços são patrimônios que precisam ser pensado a luz da pesquisa e da aprendizagem. Para Magalhães (2005, p.22) "o patrimônio cultural, enquanto testemunho do nosso passado tem assumido uma importância cada vez maior no seio da sociedade, primeiro, modernas, depois, pós-modernas".

Pensar em espaços culturais com a finalidade de atender a criança é pensar em ações educativas que pudessem ser concebidas com intencionalidades que possibilitassem a inventividade, a ludicidade, o intercâmbio e a diversidade.

\section{Mediação cultural}

A mediação cultural é aqui entendida como uma dentre as várias ações educativas que se caracterizam pela aproximação/relação da criança com os espaços, objetos, obras, artefatos, entre outros, na ação dos mediadores. Desse modo, ao abordar essa temática é necessário evidenciar conceito chave que alicerça essa prática - o diálogo - caminho encontrado para a construção de aprendizagens sensíveis. Freire (2005, p.123) sobre essa questão afirma

[...] o diálogo é a confirmação conjunta do professor e dos alunos no ato comum de conhecer e re-conhecer o objeto de estudo. Então, em vez de transferir o conhecimento estaticamente, como se fosse uma posse fixa do professor, o diálogo requer uma aproximação dinâmica na direção do objeto.

É pela ação de respeito e igualdade que se constrói conhecimento. Esse acontece por várias vias, numa relação de ideias compartilhadas.

Nesse sentido, a relação dialógica necessita de espaço nas ações de mediação por "compreender que os visitantes têm lugar nessa posicionalidade e também contribuem para criá-las com suas perguntas, suas histórias de vida, suas culturas, suas experiências, entre outras." (PUIG, 2009, p. 55). 
O mediador em um espaço cultural aprofunda os conhecimentos dos visitantes com as histórias e informações sobre obras/objetos de arte/cultura e artefatos. Sua intenção é de levar o público a uma experiência para além do que está vendo e possibilite múltiplas interpretações articulando suas memórias e subjetividades. (BURNHAM; KAI-KEE, 2011).

Outra contribuição importante no campo da mediação é a abordagem de Lima (2009), quando fala da mediação como passagem, o autor destaca a mediação enquanto um espaço/tempo, interação entre pessoas, obras e objetos culturais. Mediação como passagem pressupõe um momento singular para quem o experiencia. Essa postura considera que o momento de visitação aos espaços culturais deve ser vivenciado na sua totalidade, de corpo inteiro. $O$ autor defende um pressuposto de ação, de um público que vive "uma experiência de deslocamento, deixando de ser apenas espectador para 'assumir-se' um sujeito que reconstrói, por seus saberes e suas referências, o próprio trabalho do artista, como co-autor" (LIMA, 2009, p.147).

Essas questões são bastante relevantes para se pensar a relação de mediação cultural com seu público e na medida em que as instituições educativas que atendem a criança começam a ocupar os espaços culturais locais, há a necessidade de refletir sobre essas ações mediadoras.

A mediação cultural pressupõe, portanto, uma postura diferenciada no encontro entre educadores do museu, professores de educação infantil, gestores e comunidade, compartilhando práticas educativo-culturais.

\section{Considerações finais}

Goodson (2007), em seus estudos, enfatiza a urgência em se repensar as formas de aprender. $\mathrm{O}$ autor esclarece que não é mais possível pensar hoje numa educação que ainda se prende a velhos padrões de aprendizagens prescritivas, dizendo "[...] precisamos mudar de um currículo prescritivo para um currículo como identidade narrativa; de uma aprendizagem cognitiva prescritiva para uma aprendizagem narrativa de gerenciamento da vida". (GOODSON, 2007, p. 242)

A aprendizagem, numa visão narrativa, está inserida na educação pelo diálogo. E a mediação cultural nesse viés dá voz a todos os sujeitos envolvidos na ação 
educativa, considerando os contextos, as histórias de vida e as relações que estabelecem com seu meio, na construção de saberes.

Neste sentido, os espaços culturais, passam a ser vistos, na contemporaneidade, não apenas como depositários de um patrimônio ou de uma memória que coletam, preservam, estudam e divulgam. São também espaços relacionais entre os sujeitos e as coisas, um espaço de experiências, pesquisas e conhecimento.

Schmitt $(2011,07)$ nessa perspectiva, diz ser importante a "comunicação e relações com outras pessoas, entender, levar em conta perspectivas e sistematizações diversas são estratégias e fundamentos estabelecidos da mediação de arte". Também para Fernándes (2001) as experiências com o espaço são fundamentais para a forma que damos aos nossos processos de aprendizagem, as nossas imagens mentais e imagéticas. Relacionamos espaço, percepção, apropriação, pensamento e imaginação, elementos que sinalizam como nos situarmos nos contextos que vivemos.

Desta forma, há que se considerar que os espaços são dinâmicos e repletos de significações, e, portanto, possibilidades de aprendizagem. Por isso, é necessário que sejam flexíveis e alternativos nas propostas educacionais, a fim de promover novos olhares e novas oportunidades de as crianças aprenderem, desvelando o reencantamento do lugar e de si mesmas.

Para que a relação seja intrínseca e que aconteça é necessário o papel do mediador, propondo um questionamento sobre as relações entre a vida e a arte por meio do legado cultural.

\section{Referências}

BARBOSA, Ana Mae; COUTINHO, Rejane Galvão (Orgs.). Arte/educação como mediação cultural e social. São Paulo: Editora UNESP, 2009.

BARDIN, Laurence. Análise de conteúdo. Tradução: Luis Antero Reto; Augusto Pinheiro. São Paulo: Edições 70, 2011.

Bianconi, Maria Lucia; Caruso, Francisco. Educação não-formal. Revista Ciência e Cultura. vol. 57, nํ.4, 2005, p.20-20.

BOHN, Letícia R.D. Arte/cultura: pertencimento e construção de identidades In: PILLOTTO, Silvia S.D; BOHN, Letícia R.D. Arte/educação: ensinar e aprender no ensino básico. Joinville: Ed. Univille, 2014. 
BUJES, M. I. E.; COSTA, M. V. C. Caminhos investigativos III: riscos e possibilidades de pesquisar nas fronteiras. Rio de Janeiro: DP\&A, 2005, p. 179-197.

BURNHAM, Rika; KAl-Kee, Elliott. La enseñanza en el museo de arte: la interpretación com experinnencia. Traducción: José Wolffer y Gabriel Lara. Mexico, Instituto Nacional de Bellas Artes y Literatura/Museo Nacional de San Carlos, 1ํ Ed, 2012.

CHOMBART DE LAUWE, Marie-José. Enfant en-jeu. Les pratiques des enfants durant leur temps libre en fonction des types d’environnement et des idéologies. Paris: Editions du Centre National de la recherche scientifi que, 1976.

DAHLBERG, G.; MOSS, P.; PENCE, A. Construíndo a primeira infância: o que achamos que isto seja? In: DAHLBERG, Gunilla; MOSS, Peter; PENCE, Alan. Qualidade na educação da primeira infância: perspectivas pós modernas. Porto Alegre: Artmed, 2003.

DWBOR, F. F.; CARVALHO S.; LUPPI, D. Quem educa marca o corpo do outro. São Paulo: Cortez, 2007

FERNÁNDES, A. B. M. Imagen y estética del discurso postmoderno en tiempos de globalización. In Revista de estudos universitários. V. 27 n², Sorocaba, São Paulo: UNISO, dez./2001.

FOUCAULT, M. Vigiar e punir: história da violência nas prisões. Petrópolis: Vozes, 1987.

FLICK, Uwe. Uma introdução à pesquisa qualitativa. Trad. Sandra Netz. 2. ed. Porto Alegre: Bookman, 2004.

FREIRE, Paulo. Pedagogia do Oprimido. São Paulo: Paz e Terra, 2005.

GADOTTI, Moacir. A questão da educação formal/não formal. Sion: Institut Internacional des Droits de 1을 Enfant, 2005.

GATTI, Bernadete Angelina. Grupo focal na pesquisa em ciências sociais e humanas. Brasília: Líber Livro, 2005.

GOHN, Maria da Glória. Educação não-formal e cultura política: Impactos sobre o associativismo do terceiro setor. 4 ed. São Paulo: Cortez, 2008.

GOODSON, Ivo. Currículo, narrativa e o futuro social. Revista Brasileira de Educação. v.12, n. 35, 2007, p. 241-251.

KOHAN, Walter Omar. Infância: entre educação e filosofia. 1.ed., 1.reimp. Belo Horizonte: Autêntica, 2005.

LIBÂNEO, José Carlos. As Teorias Pedagógicas Modernas revisitadas pelo debate contemporâneo na Educação. In: LIBÂNEO, José Carlos; SANTOS, Akiko (Org.). Educação na era do conhecimento em rede e Transdisciplinaridade. Campinas: Alínea, 2005, p. 19-62.

LIMA, Joana D`Arc de S. Trocando experiências: a aventura moderna revisitada na proposta de mediação da mostra Acácio Gil Borsói e os artistas Vicente do Rego Monteiro e João Câmara. In: BARBOSA, A. e COUTINHO, Rejane Galvão. (Orgs.) Arte/Educação como mediação cultural e social. São Paulo: Unesp, 2009, p. 141-160.

MAGALHÃES, Fernando. Museus, patrimônio e identidade. Ritualidade, Educação, Conservação, Pesquisa, Exposição. Porto, PT: Profoedições, Lda./ Jornal a Página, 2005.

MARTINS, M.C.; PICOSQUE, G.; GUERRA, M. T. T. Didática do ensino de arte. São Paulo: FTD, 1998.

PÉREZ GÓMEZ, A. I. Os processos de ensino-aprendizagem: análise didática das principais teorias da aprendizagem. In: GIMENO SACRISTÁN, J.; PÉREZ GÓMEZ, A. I. Compreender e transformar o ensino. Porto Alegre: Artmed, 1998, p. 27- 47.

PUIG, Carla Padró. Modos de pensar museologias: educação e estudos de museus. In: BARBOSA, A e COUTINHO, Rejane Galvão. (Orgs.) Arte/Educação como mediação cultural e social. São Paulo: Unesp, p. 53-70, 2009.

SARMENTO, Manuel Jacinto; CERISARA, Ana Beatriz (Orgs.). Crianças e miúdos - perspectivas sócio pedagógicas da infância e educação. Porto: ASA Editores, 2004.

SARMENTO, Manuel Jacinto. Culturas Infantis e interculturalidade. In: DORNELLES, Leni Vieira (Org.). Produzindo pedagogias interculturais na infância. Petrópolis: Vozes, 2007, p.19-40. 
SCHMIDT, M. A. M. dos S. Infância: sol do mundo - A primeira conferência nacional de educação e a construção da infância brasileira. Curitiba, 1997. Tese de doutorado apresentada ao Departamento de Historia, Setor de Ciências Humanas, Letras e Artes, Universidade Federal do Paraná. Curitiba, 1997.

VAIDERGORN, Izaac. Sol e ar, de solidariedade e de arriscar: a espacialidade e a sacralidade. In: SIMSON; PARK; FERNANDES (Orgs.). Educação não-formal: cenários da criação. Campinas, SP: Editora da Unicamp, 2001, p. 14-28.

VEIGA-NETO, Alfredo. Espaços, tempos e disciplinas: as crianças ainda devem ir à escola? In: ALVESMAZZOTTI, Alda et al Linguagens, espaços e tempos no ensinar e aprender. Rio de Janeiro: DP\&A, 2000, p. 9-20.

VIÑAO FRAGO, A.; ESCOLANO, A. Currículo, espaço e subjetividade: a arquitetura como programa. Trad. Alfredo Veiga-Neto. Rio de Janeiro: DP\&A, 2001.

TAMANINI, Elizabete; PILLOTTO, Silvia Sell Duarte. Educação popular e patrimônio cultural: a complexidade do modo de construir saberes formais e não formais interdisciplinares entre museu, escola e comunidade. In: VENERA, Raquel Alvarenga Sena; CAMPOS, Rosânia (Orgs.). Abordagens teórico-metodológicas: primeiras aproximações. Joinville, SC: UNIVILLE, 2012, p. 107-128.

\section{Silvia Sell Duarte Pillotto}

Pós-Doutora no Instituto Estudos da Criança - IEC na Universidade do MINHO - UMINHO, Braga/Portugal. Doutora em Engenharia de Produção (Gestão da Qualidade) pela Universidade Federal de Santa Catarina - UFSC. Mestre em Educação (Currículo) pela Universidade Federal do Paraná - UFPR (1997) Especialista em Fundamentos Estéticos para a Arte na Educação pela Faculdade de Artes do Paraná (1992); Graduada em Educação Artística - Habilitação Artes Plásticas pela Universidade para o Desenvolvimento do Estado de Santa Catarina - UDESC (1983) Professora titular nos cursos de Artes Visuais e Pedagogia na Universidade da Região de Joinville - UNIVILLE e nos Programas de Pós-Graduação - Mestrado em Educação e Patrimônio Cultural e Sociedade; Pesquisadora e coordenadora de Núcleo de Pesquisa, possui experiência nas áreas de Artes, Gestão, Currículo, Avaliação e Arte/Educação. Avaliadora do INEP, atua nos seguintes níveis da educação: educação superior e pós-graduação. Autora de vários livros publicados, desenvolve formação continuada e consultoria nas áreas citadas.

E-mail: pillotto0@gmail.com

Currículo: http://lattes.cnpq.br/3787447361829087

\section{Letícia Ribas Diefenthaeler Bohn}

Possui graduação em História pela Universidade da Região de Joinville (2004) e Mestrado em Patrimônio Cultural e Sociedade pela Universidade da Região de Joinville (2010). Atualmente é professora dos Cursos de Design, Artes visuais e Letras da Universidade da Região de Joinville. Tem experiência na área de História, atuando principalmente nos seguintes temas: educação, infância, cultura, antropologia, sociologia, currículos e ações comunitárias.

E-mail: lebohn@gmail.com

Currículo: http://lattes.cnpq.br/6042356980628627 